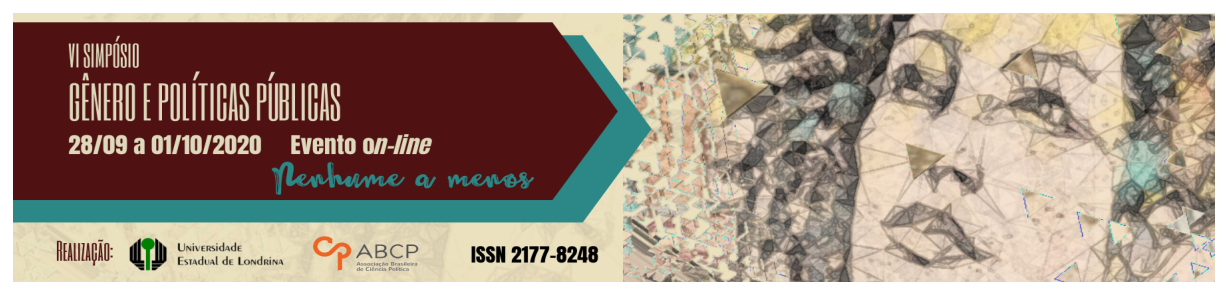

\title{
Participação social e pluralidade: mandatos coletivos como nova forma de fazer política
}

\author{
Laura Cazarini Trotta ${ }^{1}$
}

\section{Resumo}

Os mandatos coletivos surgem como um novo formato para descentralizar e despersonalizar a política. Com diferentes estratégias de campanha e dos acordos entre os co-candidatos e co-parlamentares a pluralidade a participação social estão presentes na diversidade dos ativistas que compõe esses grupos. Os objetivos do artigo são: analisar como foram as candidaturas e os mandatos coletivos eleitos, em Alto Paraíso de Goiás; na Gabinetona, em Minas Gerais, que atua em três níveis de governo; em São Paulo com a Bancada Ativista; e em Pernambuco, com as Juntas. A intenção do texto é entender de qual contexto partiu a busca por ocupação política desses grupos e como é feita a participação social, a partir dos mandatos coletivos, e como a sub-representação é enfrentada ao incluir diversidade e os movimentos sociais para participar na construção de políticas públicas. $O$ material utilizado foram sites oficiais e artigos online.

Palavras-chave: mandato coletivo; ocupação política; participação.

\section{Social participation and plurality: collective mandates as a new way of doing policies}

\begin{abstract}
Collective mandates emerge as a new format to decentralize and depersonalize politics. Using different campaign strategies and agreements between co-candidates and co-parliamentarians, the plurality of social participation is present in the diversity of activists that compose these groups.
\end{abstract}

${ }^{1}$ Mestre em Políticas Públicas pela UFABC, graduada em Relações Internacionais pela PUC Minas e Tecnologia em Gestão Pública pela UEMG. Contato: lauracazarini@gmail.com

GT 13 - Gênero, participação e representação política 
The objectives of the article are: to analyze how the collective candidatures and the collective mandates were elected, in Alto Paraíso de Goiás; Gabinetona, in Minas Gerais, which operates at three levels of government; in São Paulo with Bancada Ativista; and in Pernambuco, with Juntas. The intention of the text is to understand from which context the search for political occupation of these groups started and how social participation happens, based on collective mandates, and how underrepresentation is faced by including diversity and social movements to participate in construction of public policies. The material used were official websites and online articles.

Keywords: collective mandate; political occupation; participation.

\section{Introdução}

Os mandatos coletivos são um novo fenômeno que se apresentou na política brasileira. Esse arranjo surgiu como resposta a onda de insatisfação e interesse político da década de 2010, sendo que os primeiros casos foram em 2016, se intensificando em 2018 (SEGURADO; CHAIA; CHICARINO, 2019). Existem outros formatos que também buscam a participação mais ativa da população no cotidiano da política, são os conhecidos como "coletivos de partido" ou "compartilhados" 2. O modelo trabalhado neste artigo vem ocupando as eleições e as câmaras e assembleias, mas não se resume a uma fórmula única, pois podem apresentar diferentes formações entre os mandatos coletivos e seus participantes, podendo partir de candidaturas individuais ou coletivas quando eleitos. Com novas exigências políticas, passaram a buscar a divisão de tarefas e ideias, quebrando a lógica da política tradicional em que "o legislador tem a liberdade de votar de acordo com sua consciência e seus interesses, [já] no mandato coletivo ou compartilhado, o legislador consulta algumas pessoas para então definir seu posicionamento frente a matérias que estão tramitando nos parlamentos" (SECCHI, 2019, p. 22).

As novas propostas surgem de um contexto de mobilizações políticas e são capazes de desafiar as exclusões com a junção de

2 A população participa por votações, conselhos ou votos em aplicativos sobre determinados temas e demandas (SECCHI, 2019). 
indivíduos que representem grupos mais variados da sociedade para representarem mais pluralidade nas urnas (FARIA F., 2019). Para limitar o artigo, são tratados apenas os mandatos coletivos que foram eleitos em 2016 e 2018: o mandato coletivo mineiro, Gabinetona, que atua nos três níveis de governo - foram eleitas, em 2018, uma deputada estadual e uma deputada federal, além das duas vereadoras já em exercício dos seus mandatos, desde 2016; o de Alto Paraíso de Goiás, também eleito em 2016, no nível municipal; e mais dois mandatos que foram eleitos em 2018 para esfera estadual: a Bancada Ativista, eleita para Assembléia Legislativa de São Paulo; e o mandato Juntas, para a Assembléia Legislativa de Pernambuco. Nessa parte, além de apresentar como funcionam as relações das(os) vereadoras(es) e co-vereadoras(os); e deputadas(os) e co-deputadas(os) - Federais e Estaduais -, são detalhadas as possibilidade dos acordos e divisões, tomadas de decisão, valores difundidos e a relação dos coparlamentares com a participação da população e movimentos sociais.

A análise do texto se limita ao objetivo de entender como os novos formatos vêm atuando, desde as eleições até a vigência dos mandatos e como isso pode influenciar na participação social na construção de políticas públicas, com algumas ações destacadas. Com a característica de enfrentar a falta de representatividade nos espaços políticos essas movimentações incluem uma maior diversidade em suas equipes de candidatas(os) e assessoras(os) e também nutrem relações com os movimentos sociais, apresentados. A análise foi baseada em textos acadêmicos, mas também nos sites oficiais dos mandatos, entrevistas e outros materiais online, buscando entender a construção de cada caso desde a campanha, até as políticas propostas pelos mandatos coletivos citados.

\section{Origem e motivações das movimentações}

O levantamento bibliográfico realizado aponta um contexto comum da origem dos mandatos coletivos, em um cenário político 
global e nacional de questionamento e interesse político, junto aos movimentos sociais. Iniciadas na década de 2010, as mobilizações políticas passam a ter um alcance diferenciado, pelo acesso as redes sociais digitais, em que uma grande quantidade de indivíduos podia ser informada sobre onde e quando acontecem, de forma rápida (EUZÉBIOS FILHO; GUZZO, 2018). Dentre os principais eventos nesses formatos estão a primavera árabe, com início em 2010; outros os movimentos globais, passando pelos Estados Unidos e a Espanha, em 2011; além dos movimentos no Brasil nas conhecidas jornadas de junho, de 2013. A descrença política e o sentimento de renovação orientaram o aparecimento dessas movimentações nos contextos internacional e interno, elegendo mandatos com propostas apresentadas como inovadoras (FARIA, 2018; 2019; SEGURADO; CHAIA; CHICARINO, 2019).

Nesse contexto das manifestações do início da década, o crescente interesse da população por política estava, ao mesmo tempo, coexistindo com um desprezo com tudo que fosse político. Tal desinteresse foi um ambiente propício para o surgimento de líderes, entre estes, alguns outsiders políticos buscando se inserir no sistema, que se apresentam como distantes do jogo político. $\mathrm{O}$ novo momento de dar importância a política criou um momento de diálogo com as lutas e a construção conjunta dentro de movimentos locais, como associação de bairros, ou movimentos sociais. (FARIA, 2018; 2019; SEGURADO; CHAIA; CHICARINO, 2019). Maria da Glória Gohn define o conceito como:

Movimentos sociais são ações sociopolíticas construídas por atores sociais coletivos pertencentes a diferentes classes e camadas sociais, articuladas em certos cenários da conjuntura socioeconômica e política de um país, criando um campo político de força social na sociedade civil. As ações se estruturam a partir de repertórios criados sobre temas e problemas em conflitos, litígios e disputas vivenciados pelo grupo na sociedade. [...] [C]ria uma identidade coletiva para o movimento, a partir 
dos interesses em comum. Esta identidade é amalgamada pela força do princípio da solidariedade e construída a partir da base referencial de valores culturais e políticos compartilhados pelo grupo, em espaços coletivos não-institucionalizados. [...] [O] caráter das transformações geradas poderá ser tanto progressista como conservador ou reacionário, dependendo das forças sociopolíticas a que estão articuladas, em suas densas redes; e dos projetos políticos que constroem suas ações. (GOHN, 2004, p. 251 - 252).

Os movimentos são importantes, pois - além de criarem uma identidade coletiva, e convergência de ideias - realizam transformações quando a participação popular reflete na articulação de novos projetos políticos. A participação efetiva é um dos critérios definidos por Robert Dahl (2001; 2012) para entender o processo democrático ${ }^{3}$. A participação e a deliberação são elementos fundamentais para um aprofundamento da democracia radical, defendida por militantes de alguns dos mandatos coletivos trabalhados neste texto. Os autores Archon Fung e Joshua Cohen (2007) descrevem que existem distinções entre a democracia convencional, do que seria a democracia radical. Como a construção desses novos movimentos são experiências de inovação, as práticas da democracia também consistem em inovações e

O objetivo é promover iniciativas democráticas, dentro ou fora do Estado, que tornem os procedimentos usuais de tomada de decisão mais abertos à interferência do público por meio da razão pública. Essa defesa tem como pano de fundo a consideração dos fatos da complexidade social e seus limites à uma participação mais ampla. (FARIA, C. F., 2010, p. 107).

3 Os critérios definidos por Dahl são: a participação efetiva; a igualdade de voto; o entendimento esclarecido; o controle do programa de planejamento; e a inclusão dos adultos (DAHL, 2012). 
Assim, com os valores da democracia radical, esses mandatos defendem, como será descrito mais a frente, a participação política e a deliberação para a criação e avaliação de políticas públicas. Para Fung e Cohen:

Os cidadãos devem ter uma atuação direta mais importante nas escolhas públicas ou, ao menos, engajar-se mais profundamente nas questões políticas substantivas, tendo a garantia de que suas preocupações e opiniões serão efetivamente ouvidas e atendidas por parte dos administradores públicos. (FUNG; COHEN, 2007, p. 222).

Flávia Faria (2019) realizou estudos etnográficos acompanhando a experiência das MUITAS, em Belo Horizonte, e da Bancada Ativista, em São Paulo Para entender a participação da população em dois movimentos. Nesse estudo, a autora aponta quatro elementos comuns entre os dois grupos: (i) a política descentralizada, com a valorização da relação e confiança no coletivo, sem a mediação e sem a centralização em políticos, líderes e porta-vozes; (ii) a ocupação política, dando voz aos grupos e identidades historicamente excluídas institucionalmente; (iii) a presença de pluralidade e confluência, com diversas lutas sendo defendidas de maneira interseccional; e (iv) a participação, para que as políticas públicas sejam construídas com a participação da população, de baixo para cima (FARIA, F., 2019).

Um dos pontos principais mencionados pelos próprios participantes dos mandatos coletivos, mas também pelos apresentados como novidades políticas é o objetivo de ocupar a política, pois não se vêem representados pelas figuras da política tradicional. Porém, há diferenças nas reivindicações de representação, afinal, as movimentações que são o foco desse artigo requerem a inclusão de diferentes corpos e perspectivas de experiências de vida para a institucionalização de suas pautas. Sem a carga personalista das candidaturas no cenário eleitoral brasileiro passam a ser propostas mandatos coletivos, trazendo a possibilidade de novos pontos de partida ocuparem as cadeiras do legislativo, quebrando a lógica 
histórica da política institucional. Na descrição de cada experiência, será possível observar que existem diferentes formatos e diferentes acordos entre seus participantes - isto porque este ainda é um formato informal de mandato (CAROLINA, 2019; FLORES, 2018).

\section{Candidaturas coletivas}

Como as formas de fazer mandatos coletivos são construídas pelas experiências presentes de mandatos coletivos, o mesmo acontece no momento anterior, as candidaturas. Nas eleições já surgem propostas coletivas em diferentes formatos, afinal, não há uma previsão legal que defina esse tipo de mandato. Ainda sim, há alguns valores defendidos desde a campanha pelos mandatos focados nesse artigo - os que obtiveram sucesso nas urnas - mesmo que com diferentes formas de se declarar uma candidatura coletiva. Um desses valores é a ocupação política, para dar voz a identidades e pautas excluídas, além da pluralidade de identidades e experiências de vida, pois a maior parte dos participantes dos casos aqui estudados são pessoas que se identificam com grupos historicamente excluídos da política institucional, como mulheres, pessoas negras, indígenas, pessoas $\mathrm{LGBTQI}^{+}{ }^{4}$ e pessoa com deficiência $(\mathrm{PCD})$. Além disso, os valores defendidos muitas vezes dialogam com as lutas de movimentos sociais e da onda da renovação política, com a intenção de aumentar a participação democrática e fazer uma ocupação institucional por esses movimentos (DÚ PENTE, 2019; FARIA, 2019; SEGURADO; CHAIA; CHICARINO, 2019).

Dentre as possibilidades de candidaturas coletivas, as propostas sempre apontam para candidaturas compostas por mais integrantes. Dentro das diferentes estratégias para traçar desde a campanha eleitoral, é possível que a candidatura seja feita toda em volta de um número de candidato apenas, ou seja, todos os co-

\footnotetext{
4 Sigla para designar lésbicas, gays, bissexuais, transexuais, travestis, transgêneros, queer, interssexuais entre outras identidades, expressões e orientações de gênero.
} 
vereadores ou co-deputados que forem eleitos entram para apenas uma vaga; também existe a opção de serem lançados vários candidatos, cada um com seu número para votação, e a população vota nos seus preferidos, criando a possibilidade de escolha de mais de um mandato formal, ocupando mais do que uma cadeira - o que pode aumentar o número de cadeiras nas Câmaras e Assembleias (FLORES, 2018).

As diferentes estratégias de campanha têm suas vantagens e desvantagens. Quando a candidatura é voltada em apenas uma vaga para um grupo de pessoas, a vantagem é de concentrar votos na mesma campanha. Quando se tem várias candidaturas do grupo, tem a desvantagem de dividir os votos, pois existem mais possibilidades de nomes para serem votados; mas a vantagem está na possibilidade de se elegerem mais cadeiras para ocupar as câmaras e assembleias. Nesse sentido, o mais importante é entender qual a melhor estratégia para aquele grupo, principalmente na construção dos combinados em caso de sucesso nas urnas. Assim, serão descritas as candidaturas coletivas, que posteriormente foram eleitas:

\section{Candidatura Coletiva de Alto Paraíso de Goiás:}

Em 2016, o grupo se uniu em uma candidatura coletiva para o cargo de vereança em Alto Paraíso de Goiás. Com uma proposta inovadora, cinco amigos criaram a proposta de saírem todos em uma só chapa. O grupo estava incluído na chapa de João Yuji, que já havia se candidato antes, quando filiado à Rede, mas se filiou ao Partido Trabalhista Nacional (PTN), pois foi o partido que aceitou o projeto de mandato coletivo apresentado (TAVARES, 2016). Um dos pontos a ser sublinhado é que o partido é encarado pelos participantes como uma burocracia a ser cumprida e só passaram a conhecer o partido após a eleição. A partir do projeto apresentado, o entendimento é de que teriam certa autonomia do partido para cumprir o mandato como programado. Ou seja, não necessariamente há um diálogo do mandato 
com o partido e do partido com o mandato, mas nem todos os casos de mandatos coletivos apresentam esse posicionamento frente ao partido (BERTONI, 2016).

\section{Candidatura das MUITAS e da Gabinetona:}

A candidatura partiu de um histórico de movimentos de ocupação da cidade de Belo Horizonte. Desde movimentos para ocupar as praças e os parques da cidade, até as manifestações para defender ocupações urbanas (consequências da gestão da cidade que direcionou recursos para as áreas turísticas e mais movimentadas da cidade, para a Copa das Confederações, em 2013, e Copa do Mundo, de 2014). A partir das mobilizações sociais foram realizadas movimentações políticas de enfretamento e criados outros movimentos de ocupação da cidade de Belo Horizonte (FREITAS, 2015).

A partir da confluência de diversas lutas na cidade, em 2014, surgiu o movimento "MUITAS pela Cidade que Queremos"5. O movimento se reunia e se organizava para ocupar a cidade, além de fazer reivindicações referentes à mobilidade urbana, arte, cultura e não discriminação, o grupo entendeu que também deveriam lutar pela ocupação de ambientes políticos. Então, o próximo passo seria ocupar as eleições e, com isso, em 2016, um grupo de doze pessoas se candidatou pelo Partido Socialismo e Liberdade (PSOL). As inovações foram iniciadas já na campanha, a candidatura foi coletiva, mas diferente de apresentar apenas um número para votação e ter apenas uma pessoa oficialmente candidata, todas as doze eram candidatas. Além disso, buscavam quebrar com a lógica personalista, um dos critérios apontados anteriormente: parte do material publicitário de campanha foi feito em nomes de todos os participantes. Havia santinhos coletivos sendo distribuídos e alguns vídeos produzidos

5 Todo material usava o feminino para quem participava do coletivo, portanto, será utilizado desta forma para fazer referência ao grupo. 
apresentavam cada candidato pedindo voto pra outro participante das MUITAS. A máxima da campanha, mesmo que ainda não se tivesse certeza de como seria realizado na prática, era: "Votou em um votou em todas" (CAROLINA; FALABELLA, 2019).

Um dos objetivos do grupo era melhorar a representatividade da Câmara dos Vereadores de Belo Horizonte. Por isso, em 2016, havia diversidade nas doze candidatas: cinco LGBTQI+, oito mulheres, quatro pessoas negras e uma indígena ${ }^{6}$. Em 2018, a segunda campanha das MUITAS foi realizada para pleitear os dois níveis do legislativo em disputa: deputado estadual e federal pelo estado de Minas Gerais. A estratégia de candidaturas se manteve, porém desta vez participaram pessoas de outras cidades do estado, ainda que a concentração se mantivesse em Belo Horizonte. Das cinco candidatas a deputada federal, em 2018, quatro eram mulheres, sendo uma mulher trans ${ }^{7}$ e PcD e duas pessoas negras. Das sete candidatas ao cargo de deputada estadual eram: quatro LGBTQI+, quatro mulheres e quatro pessoas negras (DÚ PENTE, 2019).

A campanha foi majoritariamente realizada por doações, incluindo doações de peças de artistas leiloadas, em que os valores convertidos para a campanha. Para as MUITAS o PSOL foi escolhido a partir de consultas com diversos partidos ativos na cidade. Diferente do que foi visto na candidatura de Alto Paraíso de Goiás, o partido foi encarado para além de mera burocracia, mas a partir e para uma construção política, em que tanto influenciam, como podem ser influenciados pelo partido escolhido. Durante a construção para ocupação política, o projeto utilizou a estratégia de se alinhar apenas com um único partido (CAROLINA, 2019).

\footnotetext{
${ }^{6}$ Esse levantamento pretende demonstrar a diversidade como valor para o coletivo, com suas candidaturas com pessoas plurais e lutas interseccionais.

7 Mulher transexual ou travesti que se identifica como sendo do gênero feminino, embora tenha sido designada como pertencente ao gênero masculino. Diz respeito a identidade de gênero.
} 


\section{Candidatura da Bancada Ativista:}

O grupo da Bancada Ativista se uniu, no primeiro momento, nas eleições municipais de São Paulo, ainda em 2016. Os ativistas se uniram para apoiar oito candidaturas, em dois partidos diferentes, Rede e PSOL, quando Sâmia Bomfim foi eleita vereadora. Assim, equipe originou como independente de partidos, em um movimento que, a partir de seus princípios, apoiava candidaturas convergentes com seus valores. Nas eleições de 2018, a estratégia foi outra, pois definiram uma única candidatura para concorrer ao cargo de deputado estadual por São Paulo, com nove co-candidatos. Eles se entendem como um movimento suprapartidário, afinal, nem todos do grupo são filiados ao mesmo partido, ou a algum partido. $O$ movimento e o mandato conversam, mas são estruturas distintas, inclusive na questão partidária (FARIA, 2018, 2019; SEGURADO; CHAIA; CHICARINO, 2019).

A campanha da Bancada Ativista, de 2018, começou com a intenção de ocupar a política com diversas pautas somadas pelos participantes. A diversidade de corpos também estava presente, afinal, três co-candidatos eram negros, uma mulher indígena, o total de sete mulheres, uma delas é mulher trans (BANCADA ATIVISTA, 2020a). Um dos pontos interessantes da campanha é que eles afirmavam que "trariam o amor" pela política de volta aos eleitores, em um tom de resgate e não de negação da política institucional, afinal, eleger alguém é colocar a pessoa dentro do sistema. $\mathrm{O}$ formato não permite o nome de todos cadastrados pelo TSE, então, Mônica Seixas foi a escolhida para assumir oficialmente como deputada estadual, assim, foi o seu nome e sua foto que apareceu na urna eletrônica (BOCCHINI, 2018)

\section{Candidatura das Juntas:}

Formado por cinco mulheres feministas com intenção de se candidatar em 2018 e que uniram suas forças em uma só candidatura, pelo PSOL. Uma das participantes mapeou diferentes mulheres para 
realizar o convite de criar as Juntas e juntas resolveram inovar para somar suas lutas e tentar se inserir na Assembleia dos Deputados do Estado de Pernambuco (ALEPE). A candidatura apresentou três mulheres negras e uma delas, mulher trans, contando três participantes LGBT. Além dos valores de não concentração em uma figura única, a proposta parte de mulheres com perfis e perspectivas diferentes, confluindo diversas lutas, com o objetivo de aumentar a representação de mulheres na casa legislativa (MEIRELES, 2018).

\section{Mandatos coletivos}

Como já explicado, os mandatos coletivos têm formatos diferentes, afinal, diferentes acordos foram feitos entre os participantes desde a antes de propor a candidatura, formal ou informalmente. No modelo em que todos fazem parte da mesma chapa, formalmente, há a necessidade de essas candidaturas serem cadastradas no nome de apenas um dos co-candidatos, uma das intenções, além de distribuir a carga do mandato por temas ou funções, é o fato de mudar hábitos da política tradicional, em que conferia a uma só figura a responsabilidade política de liderança. Ser construído por mais pessoas cria maior inclusão, pois são mais e diferentes vivências que auxiliam na argumentação e nas decisões a serem tomadas. Esse fato pode aumentar a participação e deliberação com a população, incluindo no fazer político. Desta forma, mais indivíduos excluídos sócio histórica e institucionalmente dos ambientes políticos, mesmo ocorrendo de maneira informal (BENITES, 2018; CAROLINA, 2019; DEARO, 2018; FLORES, 2018).

Como já citado, o mandato coletivo não é apenas uma inovação em formato, mas também uma forma do fazer político. Porém, nem todos os grupos têm a proposta de enfrentamento às exclusões, com seus corpos e ideais. Também não são todos, mas muitos movimentos sociais estão associados aos mandatos e/ou aos seus participantes, que em sua maioria, se posicionam como ativistas de diversas causas. 
Assim, dentro das características de cada mandato analisadas, serão detalhadas se ocorrem e quais são as divisões entre os participantes sobre temas e funções.

Mandato Coletivo de Alto Paraíso de Goiás:

Para formalizar o acordo entre eles, o grupo registrou em cartório as regras, incluindo sobre a inclusão ou exclusão dos membros. Além disso, cada um é responsável por um tema: João Yuji é advogado e o responsável pela área jurídica, além de ser quem exerce formalmente o mandato; Laryssa Galantini, única mulher no grupo, é bióloga e ficou com as questões ligadas ao meio ambiente; Ivan Anjo Diniz é turismólogo e jornalista e também está ligado a questões culturais e artísticas, por isso se volta mais para as áreas de cultura, além do meio ambiente e de turismo; Sat Nam é professor e é o responsável pela pasta da educação; Luis Paulo Veiga, mestre em química, ficou com as funções ligadas ao turismo e ao comércio. O grupo se apresenta como uma novidade e inovação política, inclusive falaram sobre como a insatisfação com a política institucional auxiliou para a eleição da chapa. Ao pesquisar sobre a relação do mandato com as questões de gênero, foi encontrado apenas um vídeo para a campanha em que Laryssa se coloca como representante das mulheres e aponta a importância da inclusão de mais mulheres na política (BERTONI, 2016).

Além da divisão temática, no acordo dos integrantes, João Yuji, único que pode votar pelo mandato, como vereador, deve aguardar que todos levantem as mãos para votar favorável ou desfavorável. Segundo ele, se não seguir essa parte do combinado, pode ser até processado, pois faz parte do acordo formal assinado pelos cinco. Entre os temas que o grupo defende, as questões ambientais estão 
entre as principais pautas. Uma prática que chama atenção é a vereança ser um trabalho voluntário do grupo todo, pois eles firmaram que manteriam suas profissões e destinariam o salário para outros projetos voltados para a cidade (TAVARES, 2016).

\section{Mandato da Gabinetona:}

Quando Áurea Carolina, vereadora com recorde de votos em Belo Horizonte, e Cida Falabella foram eleitas, elas inovaram ao unificar seus gabinetes, tirando a divisão entre eles e criando a Gabinetona. Outra inovação da Gabinetona foi o convite de Bella Gonçalves para co-vereança, junto com Áurea e Cida. Em 2018, Bella Gonçalves assumiu o mandato quando Áurea Carolina foi candidata a deputada federal, juntamente com outros candidatos pelas MUITAS. Depois da eleição de 2018, a Gabinetona se tornou um mandato em três níveis do legislativo, na esfera municipal, estadual e federal, pois Áurea Carolina foi eleita deputada federal, juntamente com Andréia de Jesus eleita como deputada estadual (CAROLINA, 2019).

Como foi dito, na candidatura a diversidade era apresentada pelos corpos e ideais dos candidatos. Áurea Carolina é mulher negra, militante, cientista social e mestre em ciência política; Cida Falabella é professora, atriz, diretora e se envolve com questões culturais da cidade; Bella Gonçalves é lésbica, cientista social e doutora em ciência política, além de militar pelas brigadas populares; Andréia de Jesus é mulher negra, advogada popular e se envolve com a luta das periferias. Além delas, parte das candidatas das MUITAS foi contratada para participar dos mandatos como assessoras parlamentares. Por isso, a equipe dos mandatos que participam da Gabinetona é muito diversa, pois a equipe conta com mulheres, pessoas negras e indígenas, quilombolas, PcD e LGBTQI+, além de ativistas de diferentes lutas. Assim, as decisões frente às questões são tomadas de forma horizontal, levando em conta diferentes perspectivas e vivências (DU PENTE, 2019). A Gabinetona se coloca 
como um mandato popular, realizado junto à população, pois as lutas populares são mapeadas pela equipe; também são realizados laboratórios para a construção coletiva de políticas voltadas para a população; além dos editais lançados para realizar iniciativas propostas pela própria população. Tais editais são lançados como um apoio, a partir da reserva dos salários das parlamentares para financiar projetos selecionados pela equipe (CAROLINA, 2018).

\section{Mandata Ativista:}

Após o grupo da Bancada Ativista ser eleito, se denominaram como Mandata Ativista. As deliberações são realizadas de forma horizontal, com a participação das co-deputadas, mas quando são necessárias decisões mais rápidas, as resoluções são feitas pelos mais experientes nos assuntos em questão. Assim como as MUITAS, a Bancada Ativista, antes de se tornar Mandata Ativista, já era uma movimentação política que se somava a outros movimentos sociais e é constituída por ativistas. Chirley Pankará, educadora indígena e doutora em antropologia; Claudia Visoni, atuante em questões ambientais, a jornalista se volta a práticas de permacultura e questões urbanas; Erika Hilton é transvestigênere ${ }^{8}$ e militante dos direitos humanos; Fernando Ferrari, ligado a movimentos culturais e de direitos humanos; Jesus dos Santos, também milita em movimentações culturais das periferias; Mônica Seixas é uma mulher negra, mãe e feminista, além de atuar sobre questões socioambientais; Paula Aparecida, professora e militante feminista e dos direitos dos animais; Raquel Marques é doutora em Saúde Coletiva, feminista e militante em causas como melhoria do parto e empreendedorismo feminino; e Anne Rammi, foi a única a deixar a mandata até as eleições de 2020, se envolvia principalmente com questões de maternidade (BANCADA ATIVISTA, 2020b).

8 É uma expressão pela qual a co-deputada recorre e se autodenomina, portanto, é o utilizada para caracterizá-la. 
Outro ponto interessante de se destacar é a consciência coletiva sobre a inovação que estão fazendo a existência dessa mandata. Assim, a medida que a nova experiência política vai sendo vivida e construída, o grupo parte de testes para entender o que funciona na prática, com a percepção de uma política pedagógica (FARIA, 2018, 2019; SEGURADO; CHAIA; CHICARINO, 2019).

Mandato das Juntas:

As Juntas foram eleitas em 2018, com 39.175 votos para ocupar uma vaga na ALEPE. Oficialmente, o nome eleito é o de Jô Cavalcanti, mulher negra, mãe, ambulante, moradora da periferia de Recife e é ligada a movimentos sociais como Movimento dos Trabalhadores Sem Teto (MTST). As outras participantes são: Kátia Cunha, mulher lésbica, professora e militante da educação; Robeyoncé Lima, a primeira advogada transexual da região do Nordeste e passou a se envolver com questões políticas em movimentos estudantis; Carol Vergolino é produtora, jornalista e mãe e está ligada principalmente às questões culturais; Joelma Carla é bissexual, envolvida com militância voltada para juventude (JUNTAS, 2020).

Em uma entrevista, Carol Vergolino define o mandata como um "mandato ponte", justificando que os movimentos sociais são levados para dentro da ALEPE. A proposta das Juntas em ocupar a política é de fazer políticas públicas construídas com maior participação e que façam diferença na vida das pessoas (EMPODERE, 2019). Por isso, além de se posicionarem como um mandato feminista e ativista pelos direitos humanos, elas também praticam a solução de criar editais, assim como a Gabinetona, para que os projetos propostos pela população de todo o estado sejam contemplados (JUNTAS, 2020).

\section{Práticas dos Mandatos}


A pluralidade foi um ponto que apareceu em todos os casos analisados aqui, com maior importância para alguns. A identificação também apareceu nos movimentos nacionais e internacionais descritos, e é importante entender esta não pressupõe fronteiras. Isso pôde ser visto nas mobilizações para a legalização do aborto na Argentina, que uniu mulheres do mundo todo em prol dessa causa. A globalização influencia mobilizações políticas internacionais serem inspiração para lutar em outros lugares, sem uma delimitação territorial clara (FRASER, 2009). Isso pôde ser visto na construção dos mandatos coletivos, que se iniciaram em 2016, nas cidades de Alto Paraíso de Goiás e Belo Horizonte, e também inspiraram outras ações em 2018. E também estão inspirando novas possibilidades de mandatos coletivos nas eleições de 2020.

Como os mandatos coletivos são experimentações, os aprendizados vão ocorrendo junto a campanha e ao mandato, afinal, se trata de uma inovação. Mesmo inspirada em outros movimentos, ainda sim, existem adaptações à recepção do eleitorado, às regras e aos contextos das instituições nas quais se inserem esses grupos. Portanto, as práticas realizadas podem se encaixar em teorias já discorridas pela ciência política, ou apresentar-se como novidades. Ao dialogar com o texto de Fung e Cohen (2007), nas críticas apontadas ao funcionamento da participação e da deliberação, mostrando que podem existir falhas ao serem colocadas em execução, podem ser vistas práticas de democracia radical sendo realizadas pelos mandatos. Isso porque, os autores mostram estratégias para possíveis soluções dessas falhas, como os movimentos sociais, entendidos como ferramentas, que realizam a deliberação mediada. Afinal, são ações e espaços nos quais podem ser desempenhadas as deliberações com os participantes e as conclusões repassadas para outros participantes e, principalmente, para o Estado - daí vem a ideia de mediação (FUNG; COHEN, 2007). Como foi dito, os mandatos coletivos atuam como pontes, que institucionalizam as demandas dos movimentos sociais. 
Outra estratégia também é vista nas ações dos mandatos coletivos: a deliberação participativa direta. Essa dimensão é feita por meio de arranjos participativos e deliberativos locais e

se apoia na singular competência prática que têm os cidadãos enquanto usuários dos serviços públicos, sujeitos da política pública e da regulação ou moradores que têm conhecimento contextual de suas vizinhanças e ecossistemas. A ideia é basear-se nessas competências, trazendo cidadãos comuns para deliberar sobre determinadas questões públicas. Tipicamente, tais estratégias criam oportunidades para que um número limitado de cidadãos delibere entre si ou com os administradores, visando a melhorar a qualidade de alguma decisão pública. (FUNG; COHEN, 2007, p. 230).

Dentre as práticas de deliberação participativa estão os laboratórios realizados por alguns dos mandatos coletivos convocam a população para participar da criação de novas políticas. A crítica feita pelos autores, nesse caso, é a possibilidade dos pontos de vista e decisões serem relativos ao grupo de interesse que tem acesso aos espaços de deliberação e pode participar da tomada de decisões, à custa de outros cidadãos. Portanto, não necessariamente essas decisões que podem ser tomadas estarão ligadas a um bem comum local (FUNG; COHEN, 2007). Porém, com a confluência de vários movimentos e o auxílio dos mandatos, as decisões são tomadas a partir do viés previamente estabelecido, se baseando nas demandas da população.

Uma nova forma de fazer política também pode ser vista quando as parlamentares descontam uma parte de seus salários, ou totalmente, no caso de Alto Paraíso, para que esse valor volte para a população. A abertura dos editais ocorre em Belo Horizonte e em Pernambuco como uma maneira direta de participação da população junto aos mandatos, pois as equipes selecionam projetos escritos e idealizados pelos próprios cidadãos. Apesar de não entrar como 
política institucional está sendo realizada com o financiamento advindo da arrecadação institucional dos salários das deputadas. Valores como a transparência também aparecem, tem as redes sociais e os sites oficiais ${ }^{9}$ - além das praças, no caso da Gabinetona - como um ambiente informativo. Projetos, relatórios, resultados de votações, divisão orçamentária e principais ações são relatadas para apresentar o que está sendo feito para população.

\section{Considerações finais}

O artigo começou descrevendo os contextos de grandes mobilizações políticas que, dentre todas as consequências, influenciaram no surgimento dos mandatos coletivos, pelo desejo de ocupação da política por ativistas e movimentos sociais. Essa ocupação não busca apenas preencher um lugar, mas quebrar lógicas presentes nos espaços institucionalizados, levando valores caros como participação e deliberação para esses espaços. Os mandatos coletivos buscam despersonalizar e mudar o modo de fazer política, sendo pontes para a introdução de demandas populares na construção de políticas públicas e outros projetos, como instrumentos de institucionalização direta de deliberação mediada. Afinal, além de coletar as deliberações realizadas nos movimentos sociais e nos partidos, dos quais os participantes fazem parte, estão os próprios participantes inseridos institucionalmente nas casas legislativas.

Como ainda não existe formalização de um modelo padrão de mandatos coletivos, há possibilidade de criar as próprias formas de fazer, testando o que pode dar certo ou errado para os participantes. Estão sendo inseridos os valores de participação, confluência e descentralização pela ocupação desses espaços pelas novas formas de fazer políticas, a partir de experimentações. Por ser uma experiência inovadora, somando diferentes pessoas para legislar, as candidaturas e

\footnotetext{
9 Apenas o mandato coletivo de Alto Paraíso não tem um site oficial, mas também apresenta contas a população pelas redes sociais, com o Facebook e Instagram.
} 
os mandatos coletivos desafiam também a centralização política. Assim, rompem com a política tradicional ao realizar enfrentamentos em diferentes momentos e por inúmeras pautas e demandas populares.

\section{Referências}

BANCADA ATIVISTA. História. Bancada Ativista. Disponível em: https://www.bancadaativista.org/historia-bancada-ativista.html. Acesso em: 20 ago. 2020a.

BANCADA ATIVISTA. Mandata. Bancada Ativista. Disponível em: https://www.bancadaativista.org/mandata-ativista.html. Acesso em: 20 ago. 2020 b.

BERTONI, Estêvão. Como 5 pessoas 'se elegeram' para uma única vaga de vereador. Nexo Jornal. 2016. Disponível em: https:/ / www.nexojornal.com.br/expresso/2016/10/13/Como-5pessoas- $\%$ E2\%80\%98se-elegeram \%E2\%80\%99-para-uma\% C3\%BAnica-vaga-de-vereador Acesso em: 15 ago. 2020.

BOCCHINI, Bruno. Candidatura coletiva é eleita pela primeira vez em São Paulo. Agência Brasil. 2018. Disponível em: https:/ / agenciabrasil.ebc.com.br/politica/noticia/2018-

10/candidatura-coletiva-e-eleita-pela-primeira-vez-em-sao-paulo Acesso em: 15 ago. 2020.

CAROLINA, Áurea. Cenários para 2018: por uma ocupação real da política. Nexo Jornal. 2018. Disponível em: https://www.nexojornal.com.br/ensaio/2018/Cen\%C3\%A1riospara-2018-por-uma-ocupa \% C3\% A7\% C3\% A3o-real-dapol\%C3\%ADtica Acesso em: 15 ago. 2020.

CAROLINA, Áurea. Gabinetona: 4 parlamentares em um mandato coletivo, aberto e popular. O Tempo. 2019. Disponível em: https:/ / www.otempo.com.br/politica/gabinetona/gabinetona-4parlamentares-em-um-mandato-coletivo-aberto-e-popular-1.2125958 Acesso em: 2 ago. 2019.

CAROLINA, Áurea; FALABELLA, Cida. Um mandato coletivo como estratégia de resistência. Folha de São Paulo. Disponível em: 
https:/ /agoraequesaoelas.blogfolha.uol.com.br/2017/12/07/violenc ia-contra-mulheres-na-politica-aurea-e-cida/?loggedpaywall\#_=_ Acesso em: 15 ago. 2020.

DAHL, Robert A. Poliarquia: participação e oposição. Tradução de Celso Mauro Paciornick. São Paulo, SP: Edusp, 2012. 235 p., il. (Clássicos, 9). ISBN 9788531404092.

DU PENTE. Ocupar a política é o principal objetivo das Muitas desde sua criação. Carta Capital. 2019. Disponível em: https:/ / www.cartacapital.com.br/opiniao/somos-muitas-ocupar-apolitica-e-radicalizar-a-democracia/. Acesso em: 15 ago. 2020.

EMPODERE. A potência de mulheres juntas. Revista Empodere, ed. 6, p. 24-28, 2019.

Disponível

em: https:/ / uploads.strikinglycdn.com/ files/d2b08995-1be0-4dd3-8558d53993cd6d53/Empodera\%20-\%20Materia\%20Juntas.pdf Acesso em: 15 ago. 2020.

EUZÉBIOS FILHO, Antonio; GUZZO, Raquel S. L. A conjuntura após junho de 2013: olhares cruzados sobre participação política e resistência. Psicologia USP, São Paulo, v. 29 n. 2, 2018. Disponível em: http:/ / www.scielo.br/pdf/pusp/v29n2/1678-5177-pusp-29-02159.pdf Acesso em: 11 ago. 2020.

FARIA, Cláudia Feres. O que há de radical na teoria democrática contemporânea. Revista Brasileira de Ciências Sociais, v. 25, n. 73, p. 101-111, 2010.

FARIA, Flávia de. Movimentos sociais e política institucional: por uma democracia da experiência. In: Congresso Brasileiro de Sociologia, 19., 2019, Florianópolis. Anais [...]. Florianópolis: 2019. Disponível em:

http:// www.sbs2019.sbsociologia.com.br/arquivo/downloadpublic ?q=YToyOntzOjY6InBhcmFtcyI7czozNToiYToxOntzOjEwOiJJRF9B UIFVSVZPIjtzOjQ6IjE2OTAiO30iO3M6MToiaCI7czozMjoiNmU2ZTI 0MGYyZjgwODNmYmVhOWQ0NGViZGMwNjI3OGQiO30\%3D Acesso em: 20 ago. 2020.

FARIA, Flávia de. Participação, renovação e ocupação: limites da representação e experiências de transformação política na cidade de São Paulo. Revista Contraponto, v. 5, n. 1, Porto Alegre, 2018. 
FLORES, Paulo. O que é mandato coletivo. E quais os seus limites práticos e legais. Nexo Jornal, 02 de mar. de 2018. Disponível em: https:/ / www.nexojornal.com.br/expresso/2018/03/02/O-que\% C3\% A9-mandato-coletivo.-E-quais-os-seus-limitespr\%C3\%A1ticos-e-legais Acesso em: 2 ago. 2019.

FRASER, Nancy. Reenquadrando a justiça em um mundo globalizado. Lua Nova, n. 77, p. 11-39, 2009.

FREITAS. Luiz Fernando Vasconcelos de. Do Profavela à Izidora: a luta pelo direito à cidade em Belo Horizonte. 2015. 245 f. Dissertação (Mestrado em Direito) - Universidade Federal de Minas Gerais, Belo Horizonte, 2015.

FUNG, A., COHEN, J. Democracia radical. Política \& Sociedade, n. 11, p. 221-237, 2007.

GABINETONA. COMO CHEGAMOS AQUI. Gabinetona. 2018. Disponível em: https://gabinetona.org/como-chegamos-aqui/. Acesso em: 13 set. 2018.

GOHN, Maria da Glória. Abordagens teóricas no estudo dos movimentos sociais na América Latina. Caderno $C R H$, Salvador, v. 21, n. 54, p. 439-455, Set./ Dez. 2008.

GOHN, Maria da Glória. Teorias dos Movimentos Sociais - Paradigmas clássicos e contemporâneos. São Paulo: Edições Loyola, 2004.

JUNTAS. Página Inicial. Juntas. Disponível em: https:/ / www.juntascodeputadas.com.br/ Acesso em: 15 ago. 2020.

MEIRELES, Marina. 'Juntas', cinco mulheres estreiam mandato coletivo na Assembleia Legislativa de PE. G1. 2018. Disponível em: https:/ /g1.globo.com/pe/pernambuco/eleicoes/2018/noticia/2018 /10/08/juntas-cinco-mulheres-estreiam-mandato-coletivo-naassembleia-legislativa-de-pe.ghtml Acesso em: 15 ago. 2020.

SEGURADO, Rosemary; CHAIA, Vera; CHICARINO, Tathiana. Mandato coletivo: a candidatura da Bancada Ativista nas eleições de São Paulo (2018). In: MASSUCHIN, M.G.; CERVI, E.U.; CAVASSANA, F.; TAVARES, C.Q. (Org.). Comunicação e política: interfaces em esferas regionais. São Luís: EDUFMA, 2019. 
TAVARES, Altair. Grupo é eleito para "mandato coletivo" de vereador em Goiás. Diário de Goiás. 2016. Disponível em: https:/ / diariodegoias.com.br/grupo-e-eleito-para-mandatocoletivo-de-vereador-em-goias/ Acesso em: 15 ago. 2020. 